\title{
AVALIAÇÃO DA APLICAÇÃO DE AÇO DP450 EM PAINEL AUTOMOTIVO EXPOSTO*
}

\author{
Jetson Lemos Ferreira ${ }^{1}$ \\ Marco Antonio Wolff? \\ Gleyder Oliveira Bustamante ${ }^{3}$
}

\section{Resumo}

A Usiminas vem procurando fornecer aços de menor espessura ao mercado automotivo, com graus de resistência cada vez mais elevados, destacando-se os Advanced High Strength Steels (AHSS). Contudo, até então, a aplicação desses aços tem sido destinada basicamente em aplicações em peças de segurança e de reforço estrutural dos veículos. Visou-se nesse estudo avaliar, em escala laboratorial, a aplicabilidade em painel exposto de um AHSS referente ao grau DP450 em termos de conformabilidade e de desempenho, tendo como referência aços Interstitial Free (EC180) e Interstitial Free High Strength (IFHSS220). Foi verificado que o aço DP450 apresenta características mecânicas favoráveis ao processo de estampagem de componentes automotivos expostos. Para fatores que podem limitar sua utilização, tais como a flangeabilidade e o retorno elástico, foram propostas alternativas de processamento, as quais resultaram na maximização da conformabilidade do material e em melhor fixação de forma. Em termos de aplicação, verificou-se que o aço DP450 exibiu uma resistência à indentação, avaliada pela profundidade da impressão permanente, em torno de $43 \%$ e $31 \%$ superior à dos aços EC180 e IFHSS220, respectivamente.

Palavras-chave: DP450; Flangeabilidade; Retorno elástico; Painel exposto.

\section{EVALUATION OF THE DP450 STEEL APLICATION IN OUTER AUTOMOTIVE} PANEL

\section{Abstract}

The Usiminas has sought to provide thinner steel sheets to the automotive segment, with increasingly high strength grades, highlighting the Advanced High Strength Steels (AHSS). However, up to now, the application of these steels was basically in security and structural reinforcement vehicles parts. In this study was evaluated, in laboratory scale, the applicability of the DP450 steel grade (AHSS) in exposed panel in terms of formability and performance, with Interstitial Free (EC180) and Interstitial Free High Strength steels (IFHSS220) as reference. It has been found that the DP450 steel shows mechanical characteristics favorable to stamping process of the outer automotive panels. For factors that can limit their use, such as flangeability and springback were proposed alternative process, resulting in maximizing material conformability and in high form fixation. In terms of application, it was found that the DP450 steel exhibited a dent resistance, evaluated by the denting depth, around $43 \%$ and $31 \%$ higher than EC180 and IFHSS220 steels, respectively.

Keywords: DP450; Flangeability; Springback; Outer Panel.

1 Eng. Metalúrgico, M. Sc., MBA, Pesquisador, Centro de Pesquisa e Desenvolvimento da Usiminas, Ipatinga, MG, Brasil

2 Eng. Mecânico, M. Sc., MBA, Pesquisador, Centro de Pesquisa e Desenvolvimento da Usiminas, Ipatinga, MG, Brasil.

3 Eng. Metalúrgico, M. Sc., Coordenador de Assistência Técnica Usiminas, Ipatinga, MG, Brasil. 


\section{INTRODUÇÃO}

A indústria automotiva visa à redução de massa dos veículos para propiciar diminuições no consumo de combustível e na emissão de gases poluentes, além de melhorias de desempenho em termos de aceleração e em determinadas condições de impacto (menor quantidade de movimento). O papel da siderurgia nesse objetivo é fornecer aços de menor espessura, mais resistentes e com boa conformabilidade. Os aços avançados de alta resistência (Advanced High Strength Steels - AHSS) têm sido uma eficiente opção para aplicações automotivas em peças de segurança e de reforço estrutural, conjugando a redução de massa (menor espessura) com o aumento da segurança veicular (maior capacidade de absorção de energia e propiciando uma célula de sobrevivência mais resistente). Em peças expostas, que requerem elevada conformabilidade, os aços que têm sido mais intensamente empregados são os Interstitial Free de Estampagem Crítica (EC), Bake Hardenable $(\mathrm{BH})$ e os Interstitial Free High Strength (IFHSS). Contudo, como tendência vê-se a utilização de materiais sucedâneos ao aço em algumas dessas aplicações, notadamente, alumínio para capôs, portas e para-choques. Na Figura 1 são mostradas evoluções de utilização de aço, de alumínio e de outros materiais em componentes automotivos de veículos produzidos nos Estados Unidos [1].

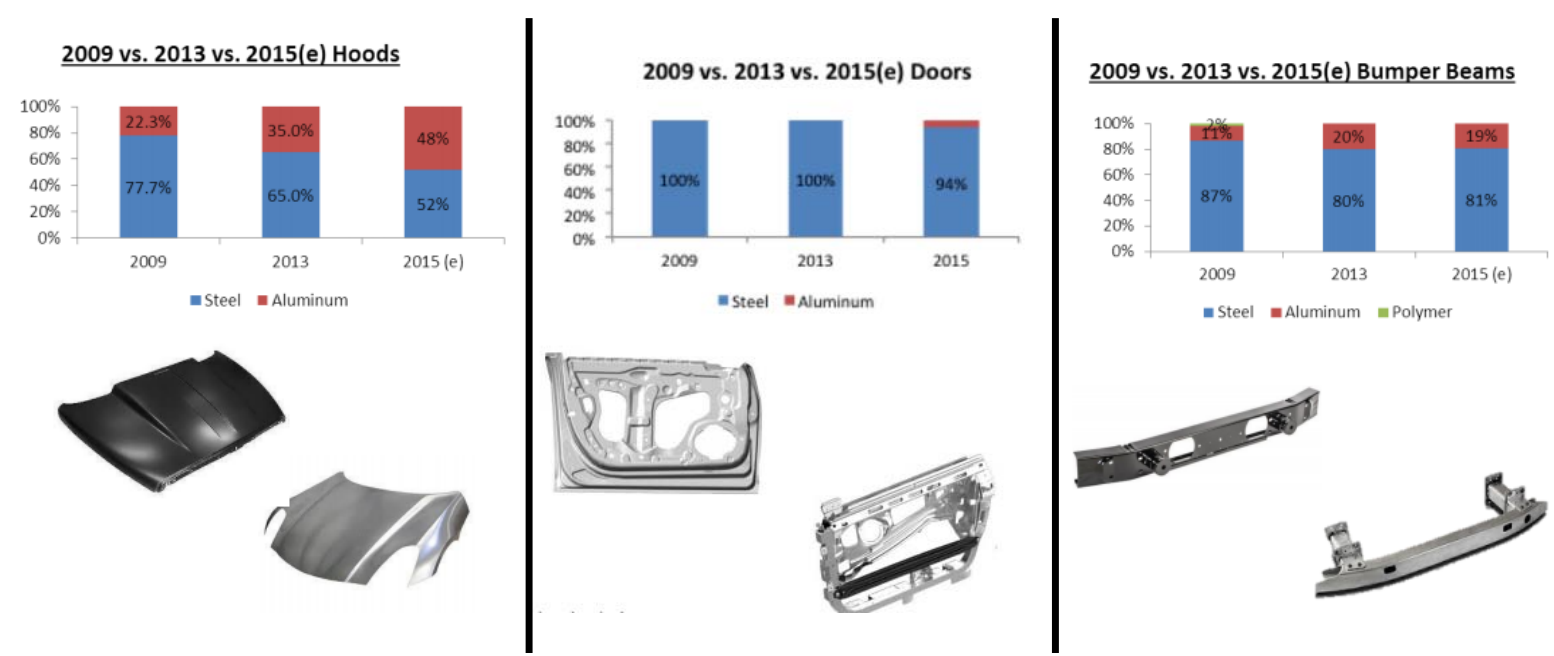

Figura 1. Evolução da utilização de materiais sucedâneos ao aço em partes de automóveis desenvolvidos nos Estados Unidos nos anos de 2009, de 2013 e de 2015 [1]

Para conter o avanço da utilização do alumínio, principalmente, em partes expostas dos automóveis que tinham, até então, o aço como material de referência, propõe-se a utilização de aços Dual Phase da classe de resistência de 450 MPa (DP450). Esse aço conjuga resistência mecânica com boa conformabilidade, propiciando ganho na resistência à indentação dos painéis. Como a resistência à indentação é um dos principais fatores de aplicação que restringem a redução de espessura do aço, reduções de massa desses componentes automotivos podem ser esperadas. Contudo, o aço DP450 apresenta menor capacidade de estiramento de flange e maior propensão ao fenômeno de retorno elástico, fatores esses que se forem negligenciados durante o processo de estampagem, podem restringir a sua aplicação.

Objetiva-se neste estudo avaliar a conformabilidade de aço DP450 comparativamente a de aços Interstitial Free de alta resistência (IFHSS220) e convencional (EC180), visando à utilização do aço Dual Phase em painéis expostos. 


\section{MATERIAIS E MÉTODOS}

Foram avaliadas amostras planas de produtos Usiminas referentes a aços dos graus DP450, IFHSS220 e EC180, todos com 1,2 mm de espessura nominal. Sabe-se que painéis automotivos de cobertura exibem espessuras bem menores do que a das amostras avaliadas, contudo, essa espessura foi utilizada por ser a menor disponível no momento de amostragem para o aço DP450. Uma vez que as microestruturas e as propriedades mecânicas em tração do aço DP450 e dos aços Interstitial Free avaliados são similares às de seus respectivos aços, produzidos em menor espessura, pode-se afirmar que a comparação, em escala laboratorial, do comportamento desses materiais de $1,2 \mathrm{~mm}$ de espessura, visando aplicação em painéis automotivos expostos, pode ser considerada válida.

A caracterização dos aços, visando à geração de informações úteis para processos de estampagem, foi realizada por meio de análises microestruturais (microscopia eletrônica de varredura), de ensaios de tração (a partir de corpos de prova sheet type da norma ASTM A370) [2], de ensaio de envelhecimento (segundo a norma ASTM A1008/A1008M) [3], de ensaio Erichsen (norma ISO 20482) [4] e da Curva Limite de Conformação (norma ISO 12004) [5].

Para a avaliação de características intrínsecas do aço DP450 que podem comprometer a estampagem (flangeabilidade), a montagem (fixação de forma) e aplicação do painel automotivo (rigidez e resistência a impressões) foram realizados, respectivamente, os ensaios de expansão de furo (norma ISO TS 16630) [6], de retorno elástico e de indentação dinâmica (norma SAE J2575) [7]. No teste hat channel empregado para a avaliação da propensão ao fenômeno de retorno elástico, ainda não se tem uma norma específica, porém as condições de ensaio adotadas foram similares às empregadas em literatura para essa avaliação [8].

\section{RESULTADOS E DISCUSSÃO}

\subsection{Caracterização dos aços avaliados}

Os constituintes microestruturais, observados na Figura 2, do aço DP450 foram ferrita (F), bainita (B) e martensita (M). Os aços IFHSS220 e EC180, conforme esperado, são compostos basicamente por ferrita.

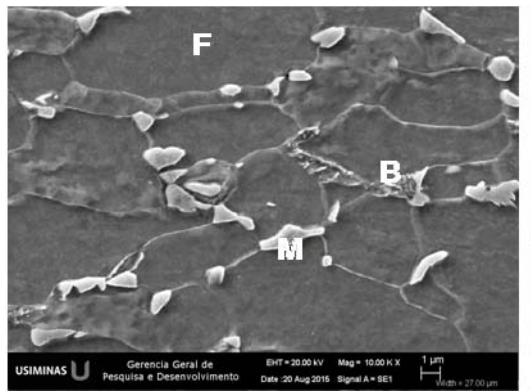

a) DP450

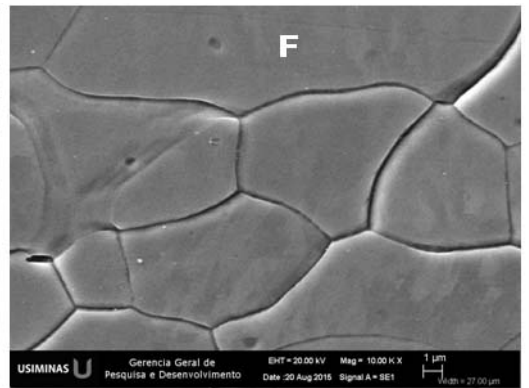

b) IFHSS220

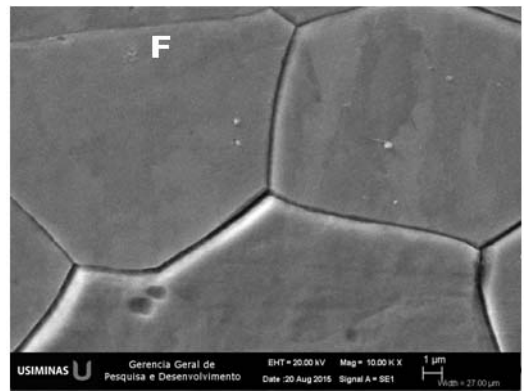

c) EC180

Figura 2. Aspecto microestrutural típico dos aços avaliados. Aumento original: 10.000x.

O aço DP450 por ser de uma classe de resistência mecânica bem superior à dos demais materiais (conforme observado na Tabela 1), exibiu valores mais baixos de alongamento (Altotal), de coeficiente de anisotropia $\left(R_{15 \%}\right)$ e de expoente de

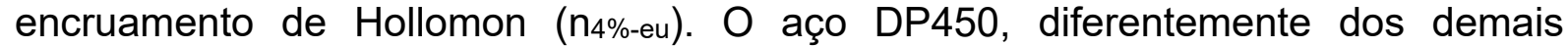
materiais, pode contar com um incremento de resistência de $43 \mathrm{MPa}$ pelo efeito 
Bake Hardening $\left(\mathrm{BH}_{2} \%\right.$ - envelhecimento acarretado pelo tratamento térmico a $170^{\circ} \mathrm{C}$ por 20 minutos). As propriedades mecânicas das amostras encontram-se de acordo com as de especificações de montadoras automotivas para cada grau de aço. $\mathrm{Na}$ Figura 3 são mostradas curvas tensão $x$ deformação de engenharia e de variação do valor $\mathrm{n}$ com a deformação verdadeira para os aços avaliados. Comparando a área sob as curvas tensão $x$ deformação, grandeza que indica a energia necessária para a deformação do material, verifica-se que, considerando a deformação até o alongamento total (Figura 4.a), o DP450 é capaz de absorver 6,9\% e 6,8\% a mais de energia do que os aços IFHSS220 e EC180, respectivamente. Quando é considerada a área até o alongamento uniforme (Figura 4.b), o aço DP450 exibe uma superioridade em relação ao IFHSS220 e EC180 em termos de capacidade de absorção de energia de $21,3 \%$ e de $21,5 \%$, respectivamente.

Tabela 1. Caracterização do comportamento mecânico dos aços avaliados por meio de ensaio de tração uniaxial.

\begin{tabular}{|c|c|c|c|c|c|c|}
\hline Aço & $\begin{array}{c}\mathrm{LE} \\
\text { (MPa) }\end{array}$ & $\begin{array}{c}\text { LR } \\
(\mathrm{MPa})\end{array}$ & $\begin{array}{c}\mathrm{Al}_{\text {total }}(\mathrm{l}) \\
(\%)\end{array}$ & $\mathbf{R}_{\mathbf{1 5 \%}}{ }^{\text {(II) }}$ & $\mathbf{n}_{10 \%-\mathrm{eu}}{ }^{(\mathrm{III})}$ & $\begin{array}{c}\mathrm{BH}_{2 \%}{ }^{(\mathrm{IV})} \\
\text { (MPa) }\end{array}$ \\
\hline DP450 & 301 & 487 & 36,0 & 1,3 & 0,20 & 43 \\
\hline IFHSS220 & 253 & 343 & 45,0 & 2,2 & 0,21 & 0 \\
\hline EC180 & 159 & 290 & 54,0 & 2,7 & 0,25 & 0 \\
\hline
\end{tabular}

(I) Alongamento total avaliado para uma base de medida de $50 \mathrm{~mm}$;

(II) Coeficiente de anisotropia avaliado com uma deformação de engenharia de15\%;

(III) Expoente de encruamento de Hollomon avaliado entre as deformações de 10\% e uniforme;

(IV) Fenômeno Bake Hardening, avaliado a 2\% de deformação.

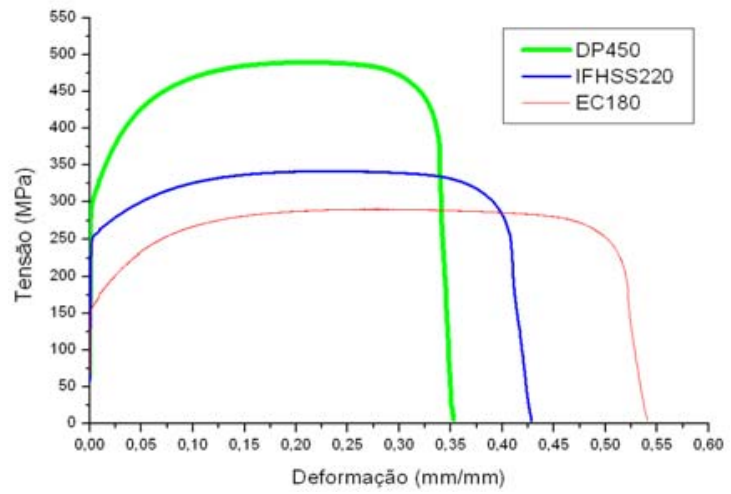

a) Curva tensão $x$ deformação de engenharia

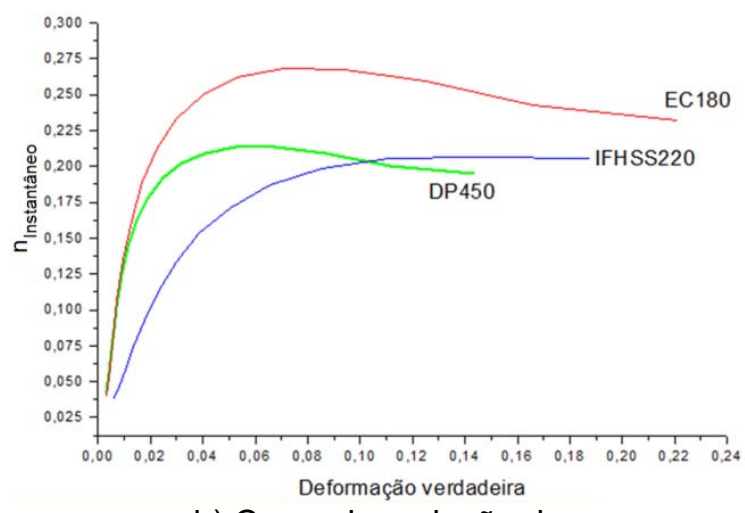

b) Curva de variação do $n$

Figura 3. Curvas tensão $x$ deformação de engenharia e de variação do expoente de encruamento de amostras dos aços avaliados submetidas a ensaio de tração uniaxial.

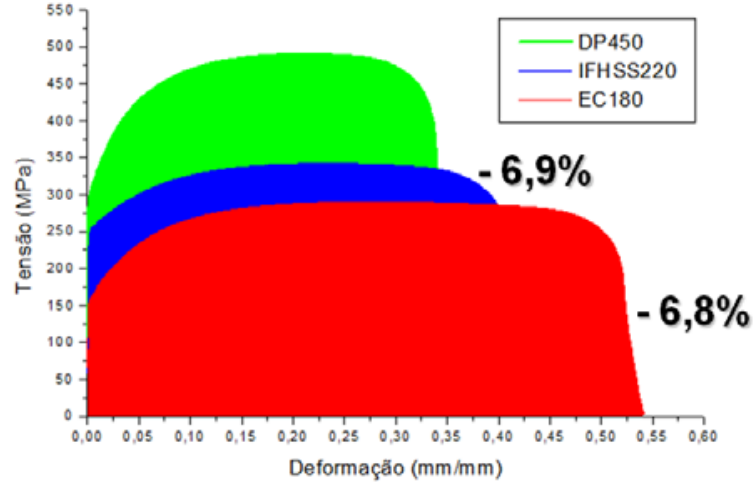

a) Alongamento total

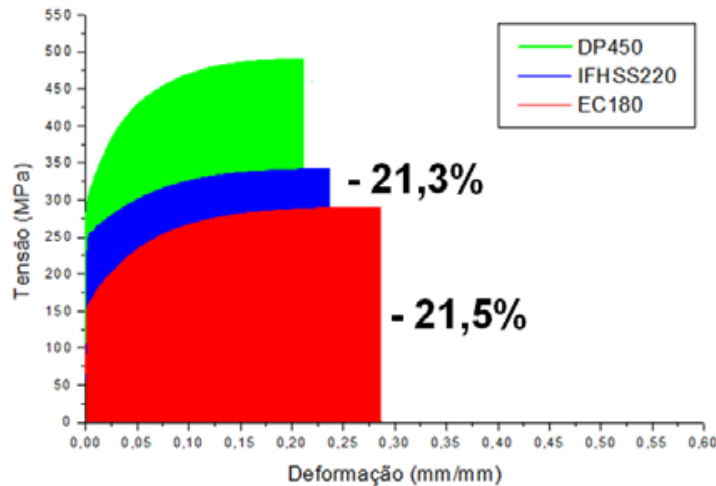

b) Alongamento uniforme

Figura 4. Comparação das áreas sob as curvas tensão $x$ deformação de engenharia de amostras dos aços avaliados, que indicam a energia absorvida para deformação. 
Os efeitos Work Hardening $\left(\mathrm{WH}_{2}\right.$ \% encruamento propiciado pela deformação em tração uniaxial de 2\%) e Bake Hardening do aço DP450 geraram juntos um incremento de resistência de $115 \mathrm{MPa}$. Como o endurecimento propiciado pelo processo de estampagem $(\mathrm{WH})$ e pelo tratamento de cura da pintura $(\mathrm{BH})$ são simulados nesse ensaio de Bake Hardenability, pode-se esperar esse aumento de resistência no painel estampado com o aço DP450, em relação a seu limite de escoamento. Na Figura 5 são mostrados os incrementos de tensão propiciados pelos efeitos $\mathrm{WH}_{2} \%$ e $\mathrm{BH}_{2} \%$ para os aços avaliados, destacando a maior resistência mecânica do aço DP450 (maior em 143 MPa que o aço IFHSS220 e em 229 MPa que o aço EC180).

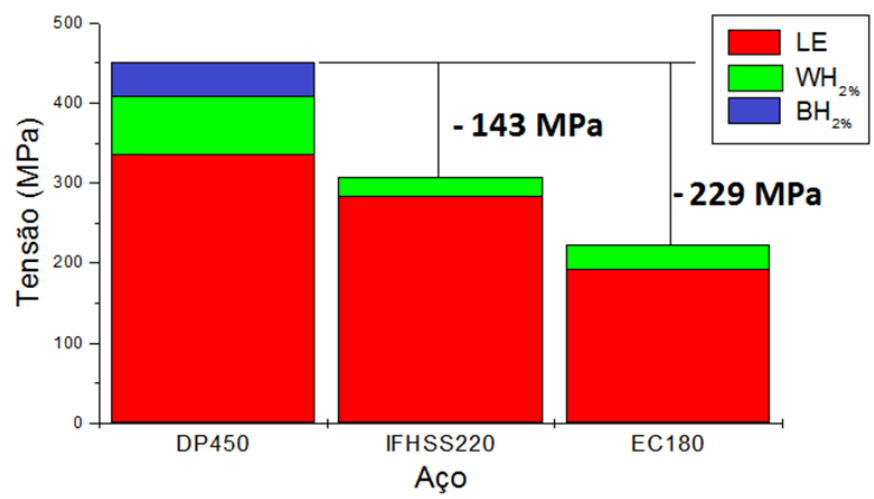

Figura 5. Incrementos de resistência propiciados pelos efeitos $\mathrm{WH}_{2} \%$ e $\mathrm{BH}_{2} \%$ para os aços avaliados.

A partir dos resultados do ensaio Erichsen, mostrados na Figura 6, verifica-se que o aço DP450 exibiu capacidade de estiramento similar à do aço IFHSS220 e inferior à do aço EC180. Para a estampagem dos materiais avaliados, verificou-se que a força máxima exercida sob estiramento biaxial do aço DP450 foi em torno de 13\% superior à máxima obtida na conformação dos demais aços.
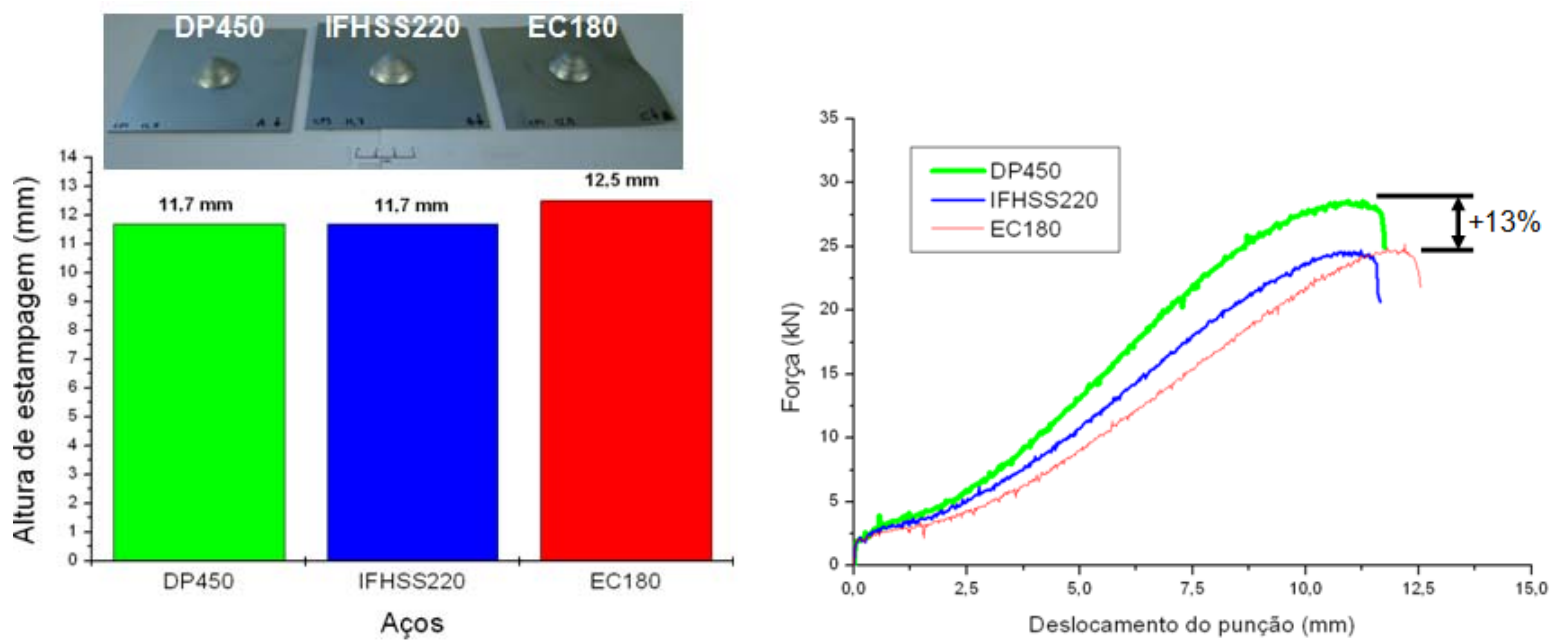

Figura 6. Resultados do ensaio Erichsen que avalia a capacidade de estiramento biaxial dos aços.

As Curvas Limite de Conformação dos aços Interstitial Free apresentaram, comparativamente à do aço DP450, valores mais elevados de $\varepsilon_{1}$ (maior deformação verdadeira), Figura 7. Contudo, para deformações positivas em $\varepsilon_{2}$ (menor deformação verdadeira) superiores a 0,1, o aço DP450 apresentou similar capacidade de estiramento ao IFHSS220. Esse comportamento é corroborado pela altura de estampagem no ensaio Erichsen e explicado pelos valores similares do 
expoente de encruamento desses aços (Figura 3.b). A quantidade de estiramento biaxial suportada pelo material apresenta relação direta com sua capacidade em distribuir as deformações, atrasando a ocorrência da estricção localizada, representada pelo expoente de encruamento do material.

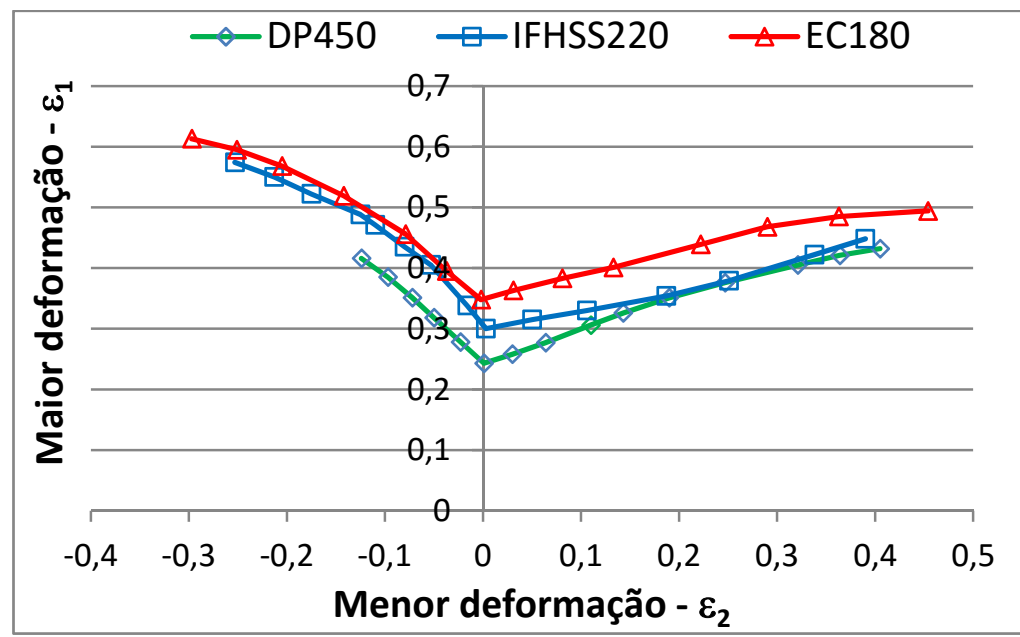

Figura 7. Curvas Limite de Conformação dos aços avaliados, determinadas pela técnica de Nakajima à estricção, seguindo as recomendações da norma ISO 12004-2 [5].

\subsection{Fatores que podem restringir a aplicação do aço DP450}

\subsubsection{Flangeabilidade}

A capacidade de estiramento de flange do aço DP450, avaliada por meio de ensaio de expansão de furo (Tabela 2), é inferior à dos demais aços avaliados. Contudo, após algumas propostas de alteração do método de confecção do furo e/ou da técnica de estampagem foram obtidas capacidades similares de estiramento de flange (Tabela 3). Observa-se também na Tabela 3, as bordas de corte de furos do aço DP450, confeccionados por diferentes metodologias, avaliadas em análise metalográfica (seção ao longo da espessura e transversal à borda de corte) e por meio de perfis de distribuição de dureza.

Percebe-se que a borda usinada, como era de ser esperar, não exibiu alterações microestruturais e de dureza. Na borda cortada a laser houve uma alteração microestrutural devido ao tratamento térmico, com profundidade de cerca de $50 \mu \mathrm{m}$. A fase formada na periferia da borda de corte foi a martensita, que resultou em um aumento de dureza local do material. Comparando a borda de corte puncionada com a recalcada, verifica-se que as imperfeições da região de fratura foram atenuadas e que as trincas foram embotadas com a adoção do recalque. A operação de recalque propiciou ainda uma maior área encruada na região adjacente à borda de corte, ou seja, as deformações não ficaram concentradas somente na região de fratura da borda de corte.

A inversão da rota de estampagem do aço DP450, estiramento biaxial seguido de furação ao invés de furação e expansão, resultou em corpos de prova de aspecto similar e com o mesmo diâmetro de furo do que os obtidos para os aços Interstitial Free. Com a adoção da inversão da rota de estampagem, visou-se utilizar a boa característica do aço DP450 em suportar estiramento biaxial. Com isso, pode-se afirmar que, em processos de estampagem submetidos a estiramento de flange, a adoção de uma dessas técnicas propostas pode maximizar a capacidade de flangeamento do aço DP450. 
Tabela 2. Resultados dos ensaios de expansão de furo ( $\lambda$ ISO), segundo a norma ISO TS 16630 [6].

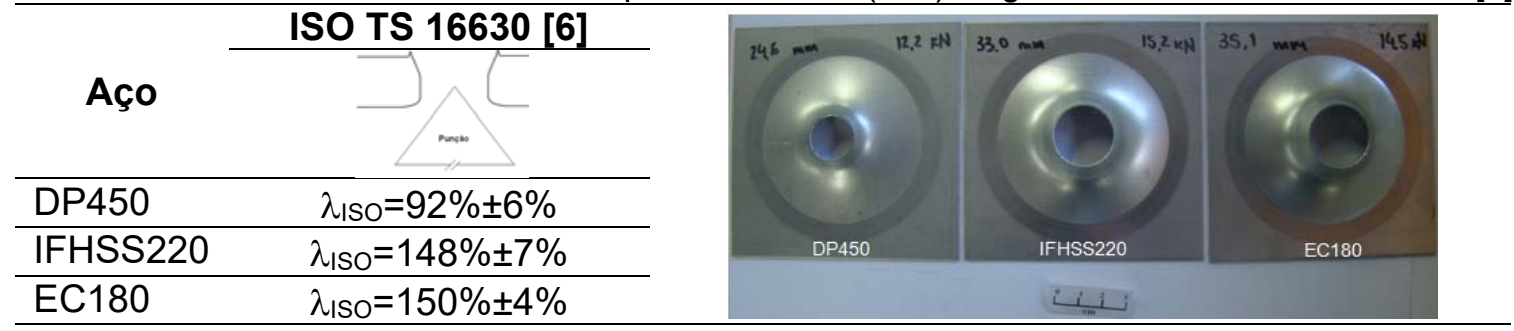

Tabela 3. Propostas de alteração do método de confecção do furo e/ou de realização dos testes de expansão de furo dos aços $(\lambda)$. Dif é a diferença entre o $\lambda$ e o $\lambda_{\text {Iso }}$ para o aço DP450.

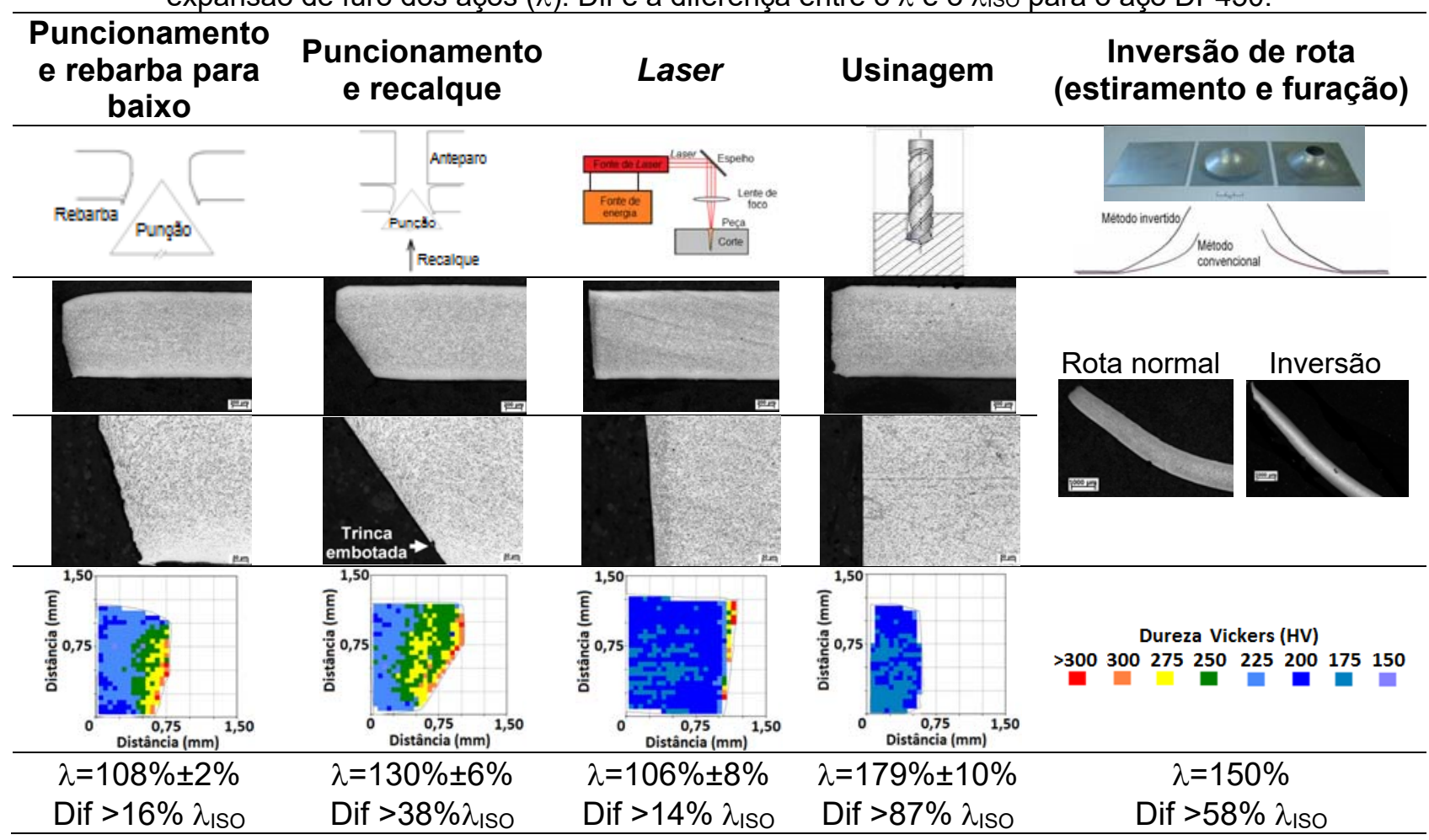

\subsubsection{Capacidade de fixação de forma}

A propensão dos aços avaliados ao fenômeno de retorno elástico foi avaliada pelo ensaio de hat channel, com matriz sem stretch-bead e com carga de prensa chapas de 35 kN. Na Figura 8 são mostrados os resultados desse ensaio de uma forma visual, por meio da comparação das geometrias finais dos corpos de prova obtidas em fotografia de aspecto.

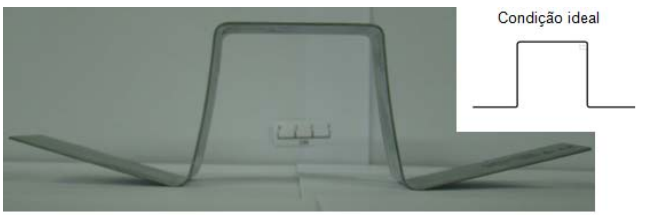

a) DP450 e representação da condição ideal

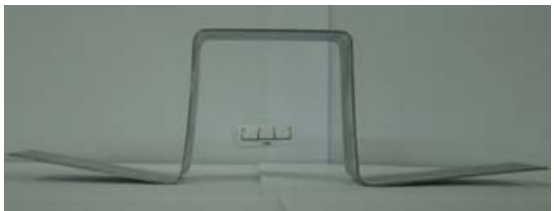

b) IFHSS220

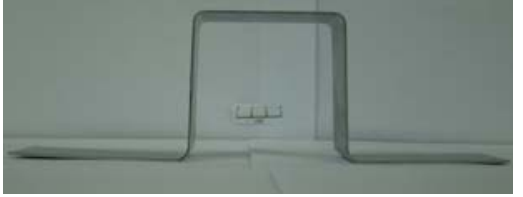

c) EC180

Figura 8. Aspecto de corpos de prova dos aços avaliados em ensaio hat channel para a determinação da propensão ao fenômeno de retorno elástico. 
A condição ideal do ensaio é de que as paredes do corpo de prova fiquem verticais e façam um ângulo próximo de $90^{\circ} \mathrm{com}$ o domo deste e com o flange. Quaisquer alterações dessa condição ideal caracterizam algum tipo de retorno elástico. Nota-se que o aço DP450 exibiu um desvio de forma da condição ideal muito maior do que os demais aços avaliados. Essa maior propensão ao fenômeno de retorno elástico do aço DP450 pode ser creditada principalmente ao seu maior limite de resistência, que faz com que a parcela de deformação elástica recuperada após a estampagem também aumente, culminando em um maior retorno elástico, Figura 9.a.

Como proposta para a redução do retorno elástico do aço DP450 foram utilizadas variações no processo de estampagem, tais como, o aumento da carga de prensa chapas, a adoção de stretch-beads e o emprego da técnica de pós-estiramento, descrita no estudo de Wolff e colaboradores [8]. Esta técnica consiste na introdução de uma deformação adicional nas paredes das peças, geralmente obtida por meio de uma maior restrição ao fluxo de material para o interior da cavidade da matriz (aumento da carga de prensa chapas para $300 \mathrm{kN}$ ), em região próxima ao final do curso do punção. Na representação esquemática mostrada na Figura 9.b, percebese que as paredes de uma peça estampada, cujo estado inicial de tensões é de tração na superfície externa (A1) e de compressão na superfície interna (B1), resulta em um gradiente de tensões elevado ao longo da espessura do material $(\Delta \sigma 1)$. Após a aplicação do estiramento adicional ao final do curso do punção, a superfície da parede sujeita à tração se move no sentido de uma tração um pouco maior (A2) e a superfície sujeita a compressão passa a ficar sob tração (B2). O diferencial de tensões se aproxima de zero $(\Delta \sigma 2)$, diminuindo a tendência à geração do retorno elástico por curvatura de parede.

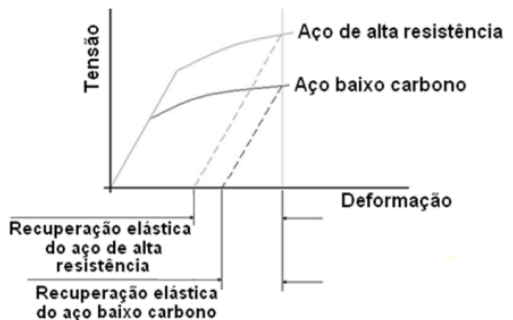

a) Recuperação elástica

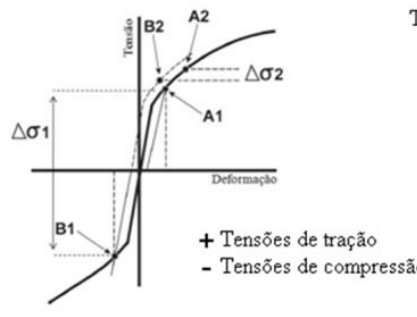

b) Redução do gradiente de tensões na espessura

Figura 9. Ilustrações a) da geração do retorno elástico por meio do carregamento e descarregamento em tração de dois aços com classes de resistência distintas e b) da redução do gradiente de tensões

ao longo da espessura do material de $\Delta \sigma 1$ para $\Delta \sigma 2$ após o processo de pós-estiramento $[8,9]$.

Na Figura 10 são mostrados os perfis obtidos por digitalização dos corpos de prova estampados pelas propostas supracitadas. Nota-se claramente que as contramedidas tomadas para a minimização do fenômeno de retorno elástico acarretaram na sua redução, cabendo destacar o efeito mais pronunciado conseguido pela técnica de pós-estiramento, com stretch bead.

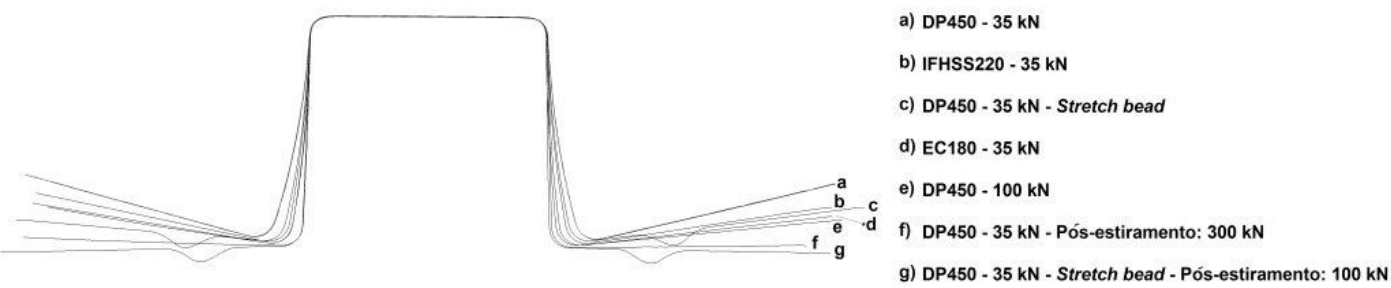

Figura 10. Perfis de corpos de prova estampados sob diferentes condições experimentais, variação da carga de prensa chapas (de 30 kN para 100 kN), utilização de matriz com stretch bead, e adoção da técnica de pós-estiramento (aumento da carga de prensa chapas para $300 \mathrm{kN}$ durante o teste). 


\subsection{Fator que favorece a aplicação do aço DP450 - Resistência à indentação}

A resistência à indentação, definida como a capacidade do painel automotivo suportar uma deformação permanente propiciada por um carregamento secundário não relacionado com a operação do veículo, pode ser considerada como o principal fator limitante da redução de espessura de painéis expostos. No presente estudo avaliou-se a resistência de corpos de prova estampados, predominantemente por tração uniaxial, à indentação dinâmica (Figura 11). Esse tipo de indentação refere-se a um impacto em alta velocidade, geralmente propiciada pela projeção de algum objeto contra a superfície do painel. Com isso, a deformação fica mais concentrada na região do impacto, na qual a profundidade da deformação permanente é o principal resultado, quanto menor melhor.

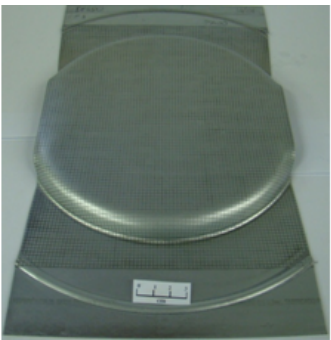

a) Aspecto

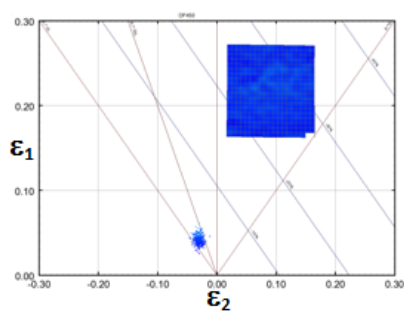

b) Pares de deformação
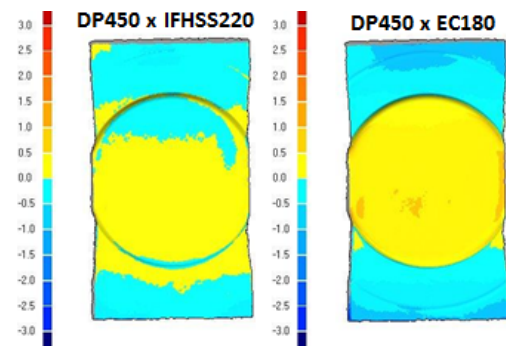

c) Comparação geométrica

Figura 11. Aspecto dos corpos de prova estampados para a avaliação da resistência à indentação.

Para o ensaio de indentação dinâmica foi utilizada uma máquina desenvolvida no Centro de Pesquisa da Usiminas [10]. A determinação da profundidade de indentação foi feita por meio da digitalização da região deformada da superfície dos corpos com auxílio de um perfilômetro (Taylor Robson CLI 1000). A partir dos resultados do ensaio de indentação, mostrados na Figura 12, verifica-se que o aço DP450 apresentou uma resistência à indentação, avaliada pela profundidade da impressão permanente, em torno de $43 \%$ e $31 \%$ superior à dos aços EC180 e IFHSS220, respectivamente.

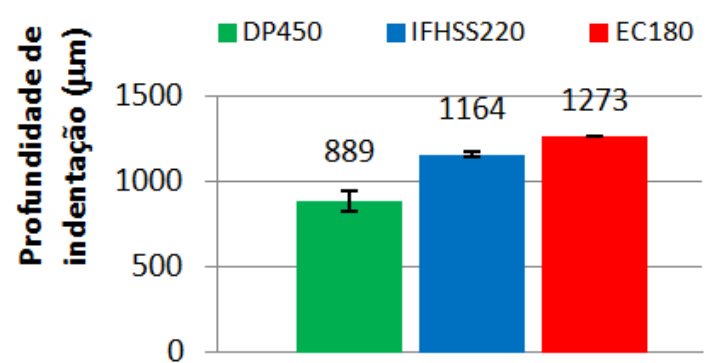

a) Profundidades médias de indentação

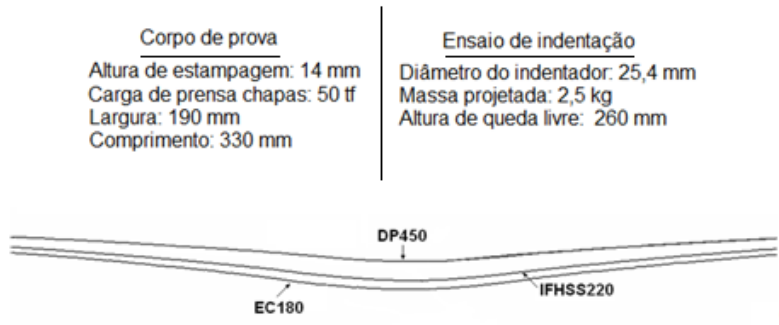

b) Perfil dos corpos de prova

Figura 12. Resultados do ensaio de indentação dinâmico em amostras dos aços avaliados.

\section{CONCLUSÃO}

Visando à aplicação em painéis expostos, o aço DP450 foi avaliado em termos de ensaios de estampabilidade, de fixação de forma e de indentação, comparativamente aos graus de aço IFHSS220 e EC180, que são normalmente aplicados nestes componentes.

Como era de se esperar em função de seu grau, o aço DP450 exibiu resistência mecânica em torno de 150 MPa maior que à do aço IFHSS220 e cerca de $200 \mathrm{MPa}$ 
superior à do aço EC180. A ductilidade do aço DP450, avaliada pelo alongamento total, foi $10 \%$ e $20 \%$ inferior à dos aços IFHSS220 e EC180, respectivamente. A menor ductilidade do aço Dual Phase também foi observada na comparação das Curvas Limite de Conformação. Contudo, observou-se que o aço DP450 exibiu capacidade de estiramento biaxial similar à do IFHSS220.

Observou-se que a flangeabilidade do aço Dual Phase pode ser aumentada pela realização de um recalque na borda do material e por meio da alteração do fluxo de processo. Ao invés de confeccionar um furo e estirá-lo, foi proposta a realização do estiramento do material seguido da furação. Por meio dessas propostas, foi conseguida capacidade de estiramento de flange compatível com a dos aços IFHSS220 e EC180.

Para a minimização do retorno elástico, a técnica em que se obteve o melhor resultado foi a de pós-estiramento. Essa técnica consiste na introdução de uma deformação adicional nas paredes das peças, geralmente obtida por meio de uma maior restrição ao fluxo de material para o interior da cavidade da matriz (aumento da força de prensa chapas), em região próxima ao final do curso do punção. Por meio dessa técnica a fixação de forma do aço DP450 foi até mesmo superior à dos aços de menor resistência mecânica avaliados.

A partir do ensaio de indentação comprovou-se o melhor desempenho do aço DP450 no que se refere a resistência à ocorrência de impressões durante impactos (menor profundidade de deformação permanente observada no painel estampado). Como a resistência à indentação é considerada um fator restritivo para a redução de espessura de painéis externos, pode-se afirmar que, com a adoção do aço DP450, componentes estampados mais finos serão conseguidos, reduzindo assim, a massa dessas peças.

\section{REFERÊNCIAS}

1 Abraham A. Metallic material trends in North American light vehicles, Ducker Worldwide, junho de 2015. Disponível em: http://www.autosteel.org/great-designs-insteel/past-gdis-presentations/gdis-2015.aspx.

2 ASTM A 370. Test methods and Definitions for Mechanical Testing of Steel Products. The American Society for Testing and Materials, 2007.

3 ASTM A1008/A1008M. Steel, Sheet, Cold-Rolled, Carbon, Structural, High-Strength Low-Alloy, High-Strength Low-Alloy with Improved Formability, Solution Hardened, and Bake Hardenable. ASTM, 2015.

4 ISO 20482. Metallic materials - Sheet and strip - Erichsen cupping test. Technical Specification, ISO, 2015.

5 ISO 12004-2. Metallic materials - Sheet and strip - Determination of forming-limit curves. Part 2: Determination of forming-limit curves. Technical Specification, ISO, 2009.

6 ISO TS 16630. Metalic Materials - Method of Hole Expanding Test. Technical Specification, ISO, 2003.

7 SAE J2575. Standardized Dent Resistance Test Procedure. SAE, 2007.

8 Wolff MA, Tepedino JOA, Silva HC, Ferreira JL. Efeito de variáveis de estampagem sobre o fenômeno de retorno elástico em aços de alta resistência, $15^{\text {a }}$ Conferência Nacional de Conformação de Chapas, 2012, Porto Alegre, RS.

9 World Auto Steel. Advanced high strength steel application guidelines. World Auto Steel (Section 2), Jun. 2009, Versão 4.1. Disponível em: www.worldautosteel.org.

10 Ferreira RF, Ferreira JL, Silva SM, Faria ER, Bustamante GO. Estudo de viabilidade de utilização do material $\mathrm{BH} 220$ em substituição ao FEP04 em painel externo de um automóvel, $67^{\circ}$ Congresso Anual da ABM, Rio de Janeiro, 2012, p.1038-1048. 